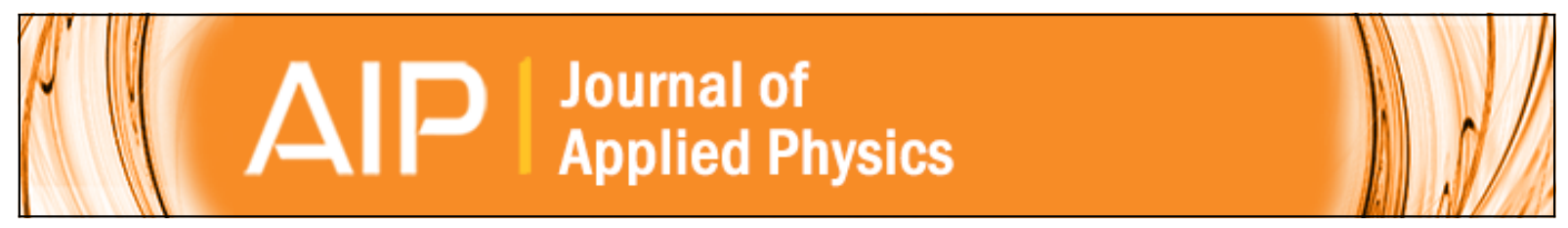

\title{
Interface structure and adhesion of wafer-bonded GaN/GaN and GaN/AIGaN semiconductors
}

Frank F. Shi, Kuo-lih Chang, K. C. Hsieh, Louis Guido, and Bill Hoke

Citation: Journal of Applied Physics 95, 909 (2004); doi: 10.1063/1.1633980

View online: http://dx.doi.org/10.1063/1.1633980

View Table of Contents: http://scitation.aip.org/content/aip/journal/jap/95/3?ver=pdfcov

Published by the AIP Publishing

\section{Articles you may be interested in}

Observations of interfaces in direct wafer-bonded InP-GaAs structures

J. Vac. Sci. Technol. B 23, 2351 (2005); 10.1116/1.2102968

Dislocation-induced nonuniform interfacial reactions of $\mathrm{Ti} / \mathrm{Al} / \mathrm{Mo} / \mathrm{Au}$ ohmic contacts on $\mathrm{Al} \mathrm{Ga} \mathrm{N/GaN}$ heterostructure

Appl. Phys. Lett. 87, 141915 (2005); 10.1063/1.2081136

Hybrid-integrated GaAs/GaAs and InP/GaAs semiconductors through wafer bonding technology: Interface adhesion and mechanical strength

J. Appl. Phys. 93, 5750 (2003); 10.1063/1.1563825

Evidence for voltage drops at misaligned wafer-bonded interfaces of AIGalnP light-emitting diodes by electrostatic force microscopy

J. Appl. Phys. 90, 4791 (2001); 10.1063/1.1406549

Structural and vibrational properties of molecular beam epitaxy grown cubic (Al, Ga)N/GaN heterostructures J. Appl. Phys. 89, 2631 (2001); 10.1063/1.1345858

\section{MIT LINCOLN} LABORATORY CAREERS

Discover the satisfaction of innovation and service to the nation
- Space Control

- Air \& Missile Defense

- Communications Systems \& Cyber Security

- Intelligence, Surveillance and

Reconnaissance Systems
- Advanced
Electronics
- Tactical Systems
- Homeland
Protection
- Air Traffic Control

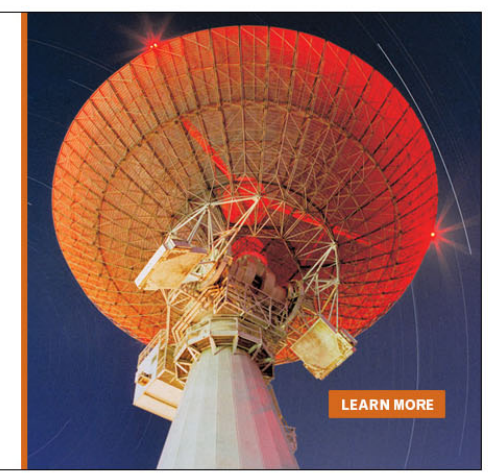




\title{
Interface structure and adhesion of wafer-bonded GaN/GaN and GaN/AIGaN semiconductors
}

\author{
Frank F. Shi, Kuo-lih Chang, and K. C. Hsieh ${ }^{\mathrm{a}}$ \\ Micro \& Nanotechnology Lab, Department of Electrical and Computer Engineering, \\ University of Illinois at Urbana-Champaign, Urbana, Illinois 61801 \\ Louis Guido \\ Department of Materials Science and Engineering, Virginia Tech, Blacksburg, Virginia 24061 \\ Bill Hoke \\ Raytheon RF Components, Andover, Massachusetts 01810
}

(Received 24 July 2003; accepted 27 October 2003)

\begin{abstract}
Material integrations of $\mathrm{GaN} / \mathrm{GaN}$ and $\mathrm{Al}_{0.25} \mathrm{Ga}_{0.75} \mathrm{~N} / \mathrm{GaN}$ semiconductors through wafer bonding technology were reported in this work. The wafer surface and interface microstructures were characterized by scanning electron microscopy and energy dispersive x-ray spectroscopy. The interface adhesion (bonding strength) was estimated based upon the interface fracture energy $\gamma_{\mathrm{o}}$ measured by double-cantilever beam technique. The interface adhesion properties of several different wafer-bonded III-V semiconductors were also compared. By comparing the atomic chemical bond energy $E_{\mathrm{o}}$ with the measured interface fracture energy $\gamma_{\mathrm{o}}$, the bondability of a few major III-V semiconductors was analyzed. (C) 2004 American Institute of Physics.
\end{abstract}

[DOI: $10.1063 / 1.1633980]$

\section{INTRODUCTION}

Group III nitride semiconductors, such as GaN, AlN, and their ternary alloy $\mathrm{Al}_{x} \mathrm{Ga}_{1-x} \mathrm{~N}$, have emerged as the leading materials for a variety of applications due to their high electron saturation velocity, high critical field, high thermal and mechanical stability, and good thermal conductivity ${ }^{1-4}$ Furthermore, the large band discontinuity creates an $\mathrm{Al}_{x} \mathrm{Ga}_{1-x} \mathrm{~N} / \mathrm{GaN}$ heterointerface that can confine an unusually high density of electrons in a two-dimensional electron gas. A modulation-doped field-effect transistor based on the $\mathrm{Al}_{x} \mathrm{Ga}_{1-x} \mathrm{~N} / \mathrm{GaN}$ heterostructures has shown encouraging high-frequency, high-power, and high-temperature performance. ${ }^{5}$ One of the major challenges in group III nitride semiconductors is the heterogeneous integration of free standing GaN-based devices with dissimilar substrates. ${ }^{3-6}$ Direct wafer bonding has been reported to be an ideal approach to integrate mismatched materials and has been used to fabricate a number of advanced microelectronic or photonic devices. ${ }^{3,4,6,7}$

Wafer bonding of $\mathrm{GaN}$ and other related semiconductors has been reported by a few research groups, such as $\mathrm{GaN} / \mathrm{GaAs},{ }^{3,4} \mathrm{GaN} / \mathrm{InP}{ }^{6}$ and $\mathrm{GaN} / \mathrm{GaN}^{7}{ }^{7}$ However, to date, only a little effort has been focused on understanding the correlations among bonding process, wafer surface or interface microstructures, and interface adhesion. This work reports on the progress toward characterizing the surface microstructures and interface adhesion of wafer-bonded $\mathrm{GaN}$ and $\mathrm{Al}_{0.25} \mathrm{Ga}_{0.75} \mathrm{~N}$ semiconductors.

\section{EXPERIMENT}

GaN wafers were fabricated by growing a 0.5 and 2.0 $\mu \mathrm{m} \mathrm{GaN} \mathrm{(0001)} \mathrm{layer} \mathrm{on} \mathrm{sapphire} \mathrm{substrates} \mathrm{using} \mathrm{metalor-}$

a)Electronic mail: k-hsieh@uiuc.edu ganic chemical vapor deposition. The $\mathrm{Al}_{0.25} \mathrm{Ga}_{0.75} \mathrm{~N}$ (0001) wafers were prepared by depositing a $1250 \AA \mathrm{Al}_{0.25} \mathrm{Ga}_{0.75} \mathrm{~N}$ over the $2.0 \mu \mathrm{m} \mathrm{GaN}$; both layers were grown by molecularbeam epitaxy on a $\mathrm{SiC}$ (111) substrate. The GaN and $\mathrm{Al}_{0.25} \mathrm{Ga}_{0.75} \mathrm{~N}$ wafers were cut into $1.0 \mathrm{~cm} \times 1.0 \mathrm{~cm}$ squares, and rinsed with acetone/methanol/isopropanol/deionized (DI) water. The wafers were then dipped into $50 \% \mathrm{HCl}$ for surface oxide removal. After final DI water rinsing and blow drying with $\mathrm{N}_{2}, \mathrm{GaN} / \mathrm{GaN}$ and $\mathrm{Al}_{0.25} \mathrm{Ga}_{0.75} \mathrm{~N} / \mathrm{GaN}$ wafer pairs were mounted together in a steel fixture. The two types of wafer pairs were bonded at $1000^{\circ} \mathrm{C}$ for $1 \mathrm{~h}$ under $\mathrm{N}_{2}$ flow. To compare the interface structures of $\mathrm{GaN}(0001) /$ $\mathrm{GaN}(0001)$ and $\mathrm{GaAs}(111) / \mathrm{GaAs}(111)$, a GaAs(111)/ $\operatorname{GaAs}(111)$ wafer pair was also bonded at $600^{\circ} \mathrm{C}$ for $1 \mathrm{~h}$. The characterization of interface adhesion by double-cantilever beam test has been reported. ${ }^{8,9}$ High-resolution scanning electron microscopy (SEM) was carried out on a Hitachi S4700 SEM. Cross-sectional transmission electron microscopy (TEM) was performed on a JEOL 2010F TEM system.

\section{RESULTS AND DISCUSSION}

Interface adhesions (interface fracture energy $\gamma_{\mathrm{o}}$ ) of wafer-bonded nitrides (this work) and other III-V semiconductors are given in Table I. Note that also included in Table $\mathrm{I}$ are atomic chemical bond energy (eV/bond $)^{10}$ and atomic interface bond energy $\left(\mathrm{J} / \mathrm{m}^{2}\right)$ for different crystalline surfaces. It is clear from Table I that the interface fracture energy $\gamma_{\mathrm{o}}$ has a proportional dependence on the interface chemical bond energy $E_{\mathrm{o}}$. The interface fracture energy of GaN/GaN or $\mathrm{Al}_{0.25} \mathrm{Ga}_{0.75} \mathrm{~N} / \mathrm{GaN}$ wafers $\left(\sim 1.2 \mathrm{~J} / \mathrm{m}^{2}\right)$ is significantly higher than that of $\mathrm{InP} / \mathrm{InP}$ or $\mathrm{GaAs} / \mathrm{GaAs}$ $\left(0.5-0.6 \mathrm{~J} / \mathrm{m}^{2}\right)$. Higher interface fracture energy of group III nitrides mainly results from two possible reasons. (1) The nature of their strong atomic chemical bonds since the adhe- 
TABLE I. Interface fracture energy $\gamma_{\mathrm{o}}$, and comparisons of the atomic bond energy $E_{\mathrm{o}}$ with interface work of adhesion $G_{\mathrm{o}}$ of a few wafer-bonded semiconductors.

\begin{tabular}{|c|c|c|c|c|c|c|}
\hline & $\operatorname{InP}$ & GaAs & GaAs (111) & $\mathrm{GaP}$ & $\mathrm{GaN}$ & $\mathrm{Ga}_{0.75} \mathrm{NAI}_{0.25}$ \\
\hline Interface fracture energy & $0.46^{[8]}$ & $0.55^{[8]}$ & 0.61 & 0.61 & 1.21 & 1.15 \\
\hline Bond energy $(\mathrm{eV} / \text { bond })^{[10]}$ & 1.74 & 1.63 & 1.63 & 1.78 & 2.24 & 2.41 \\
\hline Number of atoms $\left(\times 10^{18} / \mathrm{m}^{2}\right)$ & 5.80 & 6.27 & 7.21 & 6.73 & 7.61 & 7.71 \\
\hline Atomic bond energy $E_{\mathrm{o}}\left(\mathrm{J} / \mathrm{m}^{2}\right)$ & 3.23 & 3.27 & 3.76 & 3.83 & 5.45 & 5.95 \\
\hline Work of adhesion $G_{\mathrm{o}}\left(\mathrm{J} / \mathrm{m}^{2}\right)$ & $0.92^{[8]}$ & $1.1^{[8]}, 1.8^{[9]}$ & 1.22 & $1.22,2.34^{[9]}$ & 2.42 & 2.3 \\
\hline Ratio $G_{\mathrm{o}} / E_{\mathrm{o}}(\%)$ & $28 \%$ & $34 \%, 55 \%$ & $33 \%$ & $32 \%, 61 \%$ & $44 \%$ & $38 \%$ \\
\hline
\end{tabular}

${ }^{\mathrm{a}}$ For InP, GaAs, and GaP: face (001); for GaN and GaAlN: face (0001), or specified in the table.

${ }^{\mathrm{b}}$ The ratio will be $38 \%$ and $42 \%$ if the Young's moduli of 85.3 and 103.0 (see Ref. 12) GPa instead of 121.3 and 144.7 GPa (see Ref. 9) were used for GaAs and GaP systems, respectively.

sion of a well-fused interface is primarily determined by the strength of the newly formed interface chemical bonds during wafer bonding. ${ }^{8,9}$ The chemical bond energy of nitrides are inherently higher than that of other cubic semiconductors; that is, $2.2 \mathrm{eV}>1.7 \mathrm{eV}$. (2) The bonding surface of wurtzite group III nitrides is a close-packed plane of (0001), whose number of atoms per unit area on this plane is higher than that of a (001) plane, which is the normal bonding surface of zinc blende semiconductors, such as InP and GaAs. This higher interface atomic density can also lead to the higher surface fracture energy per unit area needed to delaminate the bonded interface for wurtzite nitrides. To verify this interface atomic density effect, the interface fracture energy $\gamma_{\mathrm{o}}$ of (111) GaAs/(111)GaAs was compared with that of $(001) \mathrm{GaAs} /(001) \mathrm{GaAs}$ and a deviation of about $10 \%$ was found; that is, 0.61 versus $0.55 \mathrm{~J} / \mathrm{m}^{2}$. This difference is reasonably consistent with the fact that the atomic density of (111)GaAs is $15 \%$ higher than that of $(001) \mathrm{GaAs}$. The relatively lower interface adhesion of the $\mathrm{Al}_{x} \mathrm{Ga}_{1-x} \mathrm{~N} / \mathrm{GaN}$ compared to $\mathrm{GaN} / \mathrm{GaN}$ is presumably due to the higher surface roughness of an $\mathrm{Al}_{0.25} \mathrm{Ga}_{0.75} \mathrm{~N}$ wafer (surface roughness rms of $6.0 \mathrm{~nm}$ for $\mathrm{Al}_{0.25} \mathrm{Ga}_{0.75} \mathrm{~N}$ versus rms of $3.0 \mathrm{~nm}$ for $\mathrm{GaN}$ ). The local topography on the wafer surface might cause the geometrically uneven distribution of bonding pressure, leading to locally high strain. It is also known that a rough surface leads to a weak direct wafer bonding, and hence is susceptible to pressure and stress, leading to interface fracture. In addition, the thermal mismatch between $\mathrm{GaN}$ and $\mathrm{Al}_{0.25} \mathrm{Ga}_{0.75} \mathrm{~N}$ could cause built-in thermal stress, also resulting in decreased interface quality.

Table I also shows the data of $G_{\mathrm{o}} / E_{\mathrm{o}}$, the ratio of interface work of adhesion $\left(G_{\mathrm{o}}=2 \gamma_{\mathrm{o}}\right)$ to atomic chemical bond energy in unit area for a few wafer-bonded semiconductors, indicating the relative strength of the wafer-bonded interfaces to the bulk semiconductors. Note that the $G_{0} / E_{\mathrm{o}}$ ratios of the wafer-bonded semiconductors are in the seemingly high range of $28 \%$ to $61 \%$. A closer examination of these numbers presented below suggests otherwise. Generally, the atomic bond energy is proportional to the cohesive energy of the crystal and thereby to the melting point. Therefore, it is worth noting that the atomic bond energy of InP $(1.74 \mathrm{eV} /$ bond) given by Ref. 10 is surprisingly high, while that of $\mathrm{GaP}(1.78 \mathrm{eV} / \mathrm{bond})$ is somewhat low. It is commonly understood that the bond energy of GaAs should be higher than that of InP. The bond energy given in Ref. 10 was obtained by adding the heat of formation (the energy required to separate the compound into elements in the standard state) to the heat of atomization of the elements. The discrepancy might be caused during the calculations. Considering the adjustment of cohesive energy, one would expect $G_{\mathrm{o}} / E_{\mathrm{o}}$ for InP to be higher and that for GaP to be smaller. Moreover, note that Young's moduli of GaAs and $\mathrm{GaP}$ used in this study is only about $70 \%$ of those used in Ref. 9. This difference should be considered when comparing the data from these two studies. If the Young's moduli of $85.3 \mathrm{GPa}$ for GaAs and 103.0 GPa for $\mathrm{GaP}$ (see Ref. 11) were used instead of 121.3 and 144.7 $\mathrm{GPa}$, respectively, ${ }^{9}$ the $G_{\mathrm{o}} / E_{\mathrm{o}}$ ratios for $\mathrm{GaAs} / \mathrm{GaAs}$ and $\mathrm{GaP} / \mathrm{GaP}$ would be about $38 \%$ and $42 \%$, instead of $55 \%$ and $61 \%$, respectively, as listed in Table I. Combined with all these considerations, the $G_{\mathrm{o}} / E_{\mathrm{o}}$ ratio of these different semiconductors would be narrowed down to roughly $30 \%-40 \%$, suggesting that, in comparison with the bulk semiconductors, the interface region only has the relative strength of about $30 \%-40 \%$. There are two factors that may account for the comparably low interface energy. (1) The wafer-bonded interface is not composed of $100 \%$ well-fused crystalline bonds. ${ }^{3,4,8,9}$ The interfacial imperfections introduce a large number of dangling bonds and a local amorphous region of about $20 \%-30 \%,{ }^{8}$ forming many local weakly bonded interface areas, which can certainly reduce the overall interface adhesion. It is worth noting that the prebonding semiconductor interfaces in Ref. 9 were cleaned in situ with hydrogen and bonded in a vacuum. Consequently, neither interface oxide nor amorphous interface layer/nanoinclusions was observed. One would expect a higher interface adhesion from these samples (listed in Table I). (2) Even for a well-fused interface, such as that in Ref. 9 and that shown in Fig. 1, compared with the bulk crystalline region, its interface fracture energy is still very low. This is presumably due to the imperfections, such as point defects and impurities, as well as to the screw dislocations and the lattice distortion induced by interface misalignment, capped along the interface region, which can result in a weaker crystalline boundary. ${ }^{8}$ Between these two factors, the latter accounts predominately for the resultant low interface fracture energy.

Figures 1(a) and 1(b) show the high-resolution SEM and cross-sectional TEM images on the wafer-bonded interface of a $\operatorname{GaAs}(111) / \mathrm{GaAs}(111)$ semiconductor prepared at $600{ }^{\circ} \mathrm{C}$, while Fig. 2 presents the interface of a wafer-bonded $\mathrm{GaN} / \mathrm{GaN}$ and $\mathrm{Al}_{0.25} \mathrm{GaN}_{0.75} / \mathrm{GaN}$ samples prepared at 

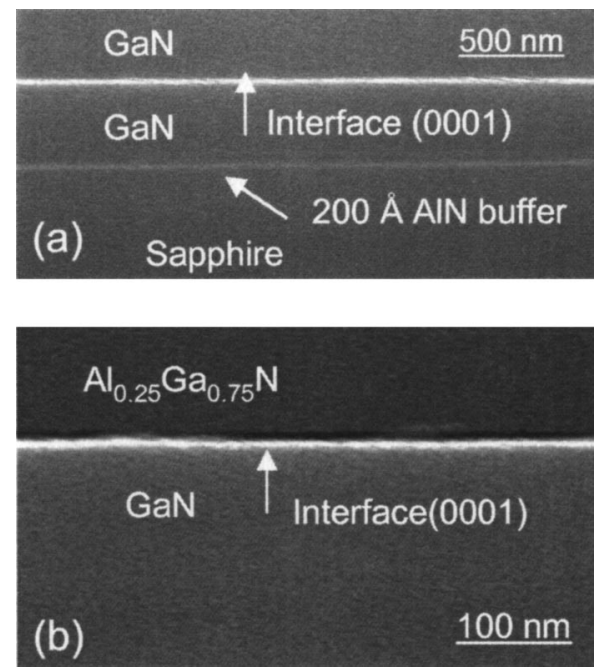

FIG. 1. (a) High-resolution SEM image of the interfaces of the waferbonded $\mathrm{GaAs}(111) / \mathrm{GaAs}(111)$. (b) Cross-sectional TEM image of the interfaces of the wafer-bonded GaAs(111)/GaAs(111).

$1000^{\circ} \mathrm{C}$ for $1 \mathrm{~h}$. Both SEM and TEM images of GaAs(111)/ GaAs(111) and a SEM image of GaN/GaN indicate uniform and well-bonded interfaces. The amorphous nanoinclusions observed in $\operatorname{GaAs}(001) / \mathrm{GaAs}(001), \operatorname{GaAs}(001) / \mathrm{InP}(001)$, and $\mathrm{GaAs}(001) / \mathrm{GaN}$ bonded interfaces ${ }^{3,8}$ were not seen in the GaAs(111)/GaAs(111) system. Even though the TEM interface image of $\mathrm{GaN} / \mathrm{GaN}$ is not available in this study, it is reasonable to expect that the $\mathrm{GaN} / \mathrm{GaN}$ interface would also show a similar uniform boundary. The different interface morphologies of wafer-bonded (001) and (111) surfaces might indicate that the atomic diffusion mechanism and driv-
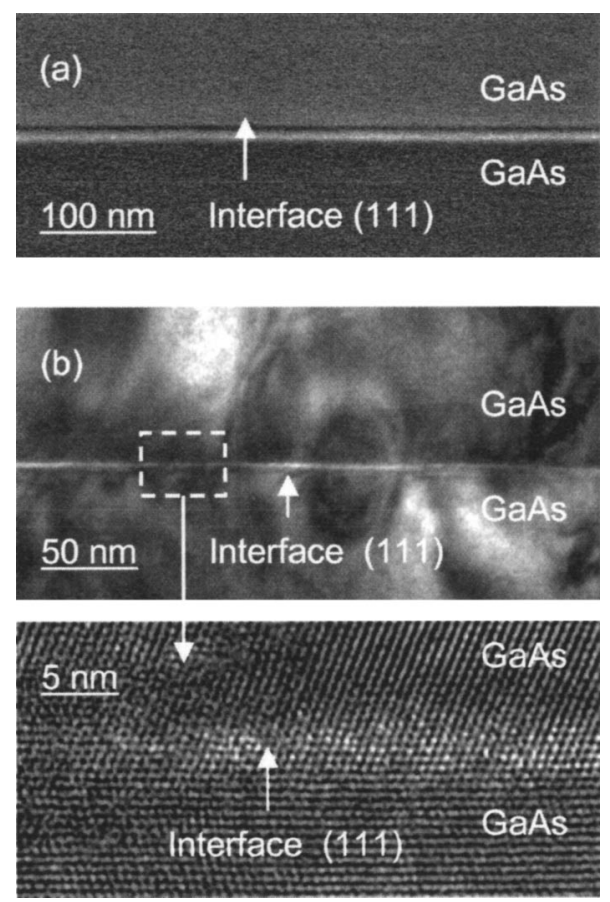

FIG. 2. High-resolution SEM image of the interface of the wafer-bonded (a) $\mathrm{GaN} / \mathrm{GaN}$ and (b) $\mathrm{Al}_{0.25} \mathrm{GaN}_{0.75} / \mathrm{GaN}$. Both were bonded at $1000{ }^{\circ} \mathrm{C}$ for 1 h.
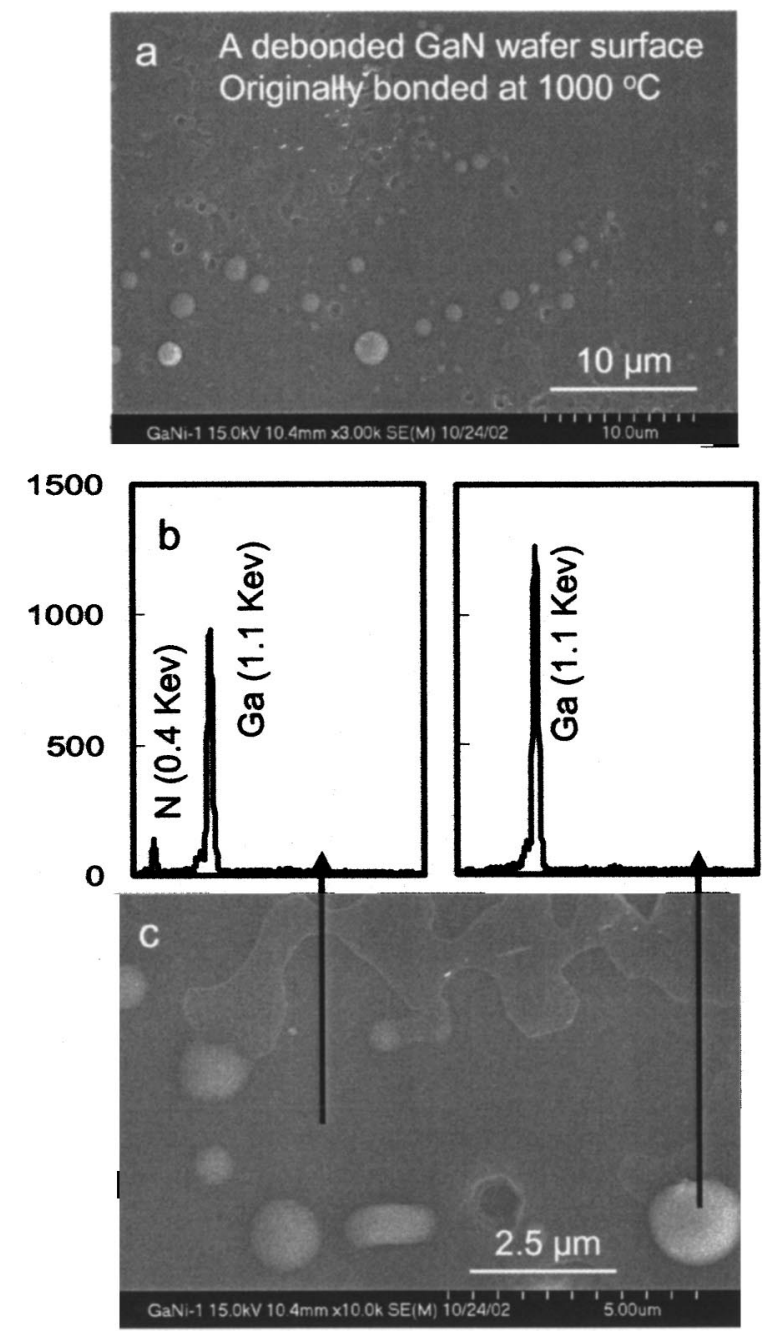

FIG. 3. (a) SEM image of a debonded GaN wafer surface showing Ga droplets due to GaN dissociation and Ga extraction. (b) The EDX spectra, showing the different chemical compositions at different locations. (c) SEM image in (a) with a larger magnification.

ing force requirement on the different crystalline planes during wafer bonding process are kinetically different, resulting in the different interface structures.

Figure 3 shows the SEM images of a debonded GaN wafer surface and the chemical compositions at different surface locations presented by the spectra of energy dispersive $\mathrm{x}$-ray (EDX). Due to the GaN dissociation at bonding temperature and the poor wettability of Ga on the GaN surface, the $\mathrm{Ga}$ droplets with micron sizes were randomly localized on the wafer surface after nitrogen desorbed from the wafer interface region. This indicates that wafer bonding of nitrides at high temperature $\left(\sim 1000^{\circ} \mathrm{C}\right)$ might cause serious interface deteriorations such as Ga segregation. Developing a low-temperature bonding approach is therefore essential for future integration of nitride semiconductors through waferbonding technology.

\section{SUMMARY}

In summary, strong direct wafer bonding of the group III nitrides was typically created at $1000^{\circ} \mathrm{C}$. However, the $\mathrm{Ga}$ droplets due to $\mathrm{GaN}$ dissociation and $\mathrm{Ga}$ segregation were 
observed on the debonded $\mathrm{GaN}$ wafer surface. Interface fracture energies $\gamma_{\mathrm{o}}$ of bonded group III nitrides are higher than those of other bonded III-V semiconductor wafers due to the nature of their stronger chemical bonds. It was also observed that wafer-bonded interface strength is typically about $30 \%-$ $40 \%$ of the bulk semiconductor area, which mainly resulted from the large density of imperfections at the interface boundary. Wafer-bonded (001) and (111) surfaces show different interface structures, suggesting that the atomic diffusion mechanism and driving force requirement on the different crystalline planes during wafer bonding process may be kinetically different.

\section{ACKNOWLEDGMENTS}

The authors would like to thank the technical support from the staff in the Center of Microanalysis for Materials at UIUC, which is supported by the U.S. Department of Energy under Grant No. DEFG02-91-ER45439. This work is supported by DARPA under Grant No. MDA 972-00-1-0020.
${ }^{1}$ S. J. Pearton, J. C. Zolper, R. J. Shul, and F. Ren, J. Appl. Phys. 86, 1 (1999).

${ }^{2}$ S. P. Denbaars, Proc. IEEE 85, 1740 (1997).

${ }^{3}$ J. Jasinski, Z. Liliental-Weber, S. Estrada, and E. Hu, Appl. Phys. Lett. 81, 3152 (2002).

${ }^{4}$ S. Estrada, H. Xing, A. Stonas, A. Huntington, U. Mishra, S. DenBaars, L. Coldren, and E. Hu, Appl. Phys. Lett. 82, 820 (2003).

${ }^{5}$ J. B. Webb, H. Tang, S. Rolfe, and J. A. Bardwell, Appl. Phys. Lett. 75, 953 (1999).

${ }^{6}$ R. K. Sink, S. Keller, B. P. Keller, D. I. Babic, A. L. Holmes, D. Kapolnek, S. P. DenBaars, J. E. Bowers, X. H. Wu, and J. S. Speck, Appl. Phys. Lett. 68, 2147 (1996).

${ }^{7}$ T. Tokuda and S. Noda, Jpn. J. Appl. Phys. 39, L572 (2000).

${ }^{8}$ F. Shi, S. MacLaren, C. Xu, K. Y. Cheng, and K. C. Hsieh, J. Appl. Phys. 93, 5750 (2003).

${ }^{9}$ T. Akatsu, A. Plöß1, R. Scholz, H. Stenzel, and U. Gösele, J. Appl. Phys. 90, 3856 (2001).

${ }^{10}$ W. A. Harrison, Electronic Structure and Properties of Solids (Freeman, San Francisco, 1980).

${ }^{11}$ M. Levinstein, S. Rumyantsev, and M. Shur, Handbook Series on Semiconductor Parameters (World Scientific, London, 1999); http:// www.ioffe.ru/SVA/NSM/Semicond/. 